\title{
Quantitative dam break analysis on a reservoir earth dam
}

\author{
${ }^{1 *}$ F. W. L. Kho; ${ }^{1}$ P. L. Law; ${ }^{2}$ S. H. Lai; ${ }^{1}$ Y. W. Oon; ${ }^{1}$ L. H. Ngu; ${ }^{1}$ H. S. Ting \\ ${ }^{1}$ Department of Civil Engineering, University of Malaysia Sarawak, Sarawak, Malaysia \\ ${ }^{2}$ Urban Drainage and River Engineering Research Center, University of Science Malaysia, Penang, Malaysia
}

\begin{abstract}
Received 6 May 2008; $\quad$ revised 27 December 2008; accepted 22 January 2009; available online 1 March 2009
ABSTRACT: Mathematical simulations on dam break or failure using BOSS DAMBRK hydrodynamic flood routing dam break model were carried out to determine the extent of flooding downstream, flood travel times, flood water velocities and impacts on downstream affected residences, properties and environmental sensitive areas due to floodwaters released by failure of the dam structure. Computer simulations for one of the worse-case scenarios on dam failure using BOSS DAMBRK software accounted for dam failure, storage effects, floodplains, over bank flow and flood wave attenuation. The simulated results reviewed a maximum flow velocity of $2.40 \mathrm{~m} / \mathrm{s}$ with a discharge of approximately $242 \mathrm{~m} 3 / \mathrm{s}$ occurred at $1.00 \mathrm{~km}$ downstream. The maximum discharge increased from $244 \mathrm{~m}^{3} / \mathrm{s}$ (flow velocity $=1.74 \mathrm{~m} / \mathrm{s}$ occurred at $8^{\text {th. }} \mathrm{km}$ ) to $263 \mathrm{~m}^{3} / \mathrm{s}$ (flow velocity $=1.37 \mathrm{~m} / \mathrm{s}$ occurred at $12^{\text {th. }} \mathrm{km}$ ); about a $39 \%$ drop in flow velocity over a distance of $4.00 \mathrm{~km}$ downstream. If the entire dam gives way instantly, some spots stretching from $0.00 \mathrm{~km}$ (at dam site) to approximately $3.40 \mathrm{~km}$ downstream of the dam may be categorized as "danger zone", while downstream hazard and economic loss beyond $3.40 \mathrm{~km}$ downstream can be classified as "low” or "minimal” zones.
\end{abstract}

Keywords: Modeling, hydrodynamic, broad-crested weir, routing, flood waves

\section{INTRODUCTION}

From 1946 to 1955, a total of 12 major dam failures were recorded and during the same period of time more than 2,000 dams were constructed worldwide. From years 1956 to 1965, a record of 24 failures and more than 2,500 new dams were constructed during the same period of time (Jansen, 1988). Johnson and Illes (1976) summarized 300 dam failures throughout the world. Dam failure can be primarily attributed to number of major key factors including earthquake, differential settlement, seepage, overtopping, dam structure deterioration, rockslide, poor construction and sabotage (Rico et al., 2008a; Rico et al., 2008b; Turahim and Mohd, 2002). Even though, the probability of dam failure can be extremely low, but its occurrences can imply catastrophic consequences downstream, including loss of human lives, properties, natural resources and so on. Therefore, significant predictive data on hypothetical flood events such as flood flows, flow velocities, depths and flood wave arrival times at specific locations downstream of the dam become some the most important pieces of information for disaster

*Corresponding Author Email: frexwl@gmail.com

Tel.: +6082 456 877; Fax: +6082 456577 preparedness such as for the formulation of emergency response plan (ERP) guidelines (Turahim and Mohd, 2002). General international practices on dam safety would include procedures that suit practical management of the dam conditions such as sending early warning and notification messages of emergency situation to the authorities, as well as information on inundation of critical areas for action in case of emergency (Ecosol, 2001). Generally, dam break analysis aims at predicting downstream hazard potential systematically in equitable approaches (BOSS International, 1999; Turahim and Mohd, 2002; Wang and Bowles, 2006). Numerical modelling process simulations can be carried out based on the topography of a catchment area using an appropriate grid size of approximately 200 m (BOSS International, 1999; Singh, 1996). Generally, a scenario discharge may be assumed in the simulation and flood affected areas may be predicted over a distance of $25.00 \mathrm{~km}$ downstream of the dam, and 1.00 to $2.00 \mathrm{~km}$ in width (BOSS International, 1999; Tingsanchali and Chinnarasri, 2001; Turahim and Mohd, 2002; Wurbs, 1987). Currently, there are a number of dam break simulation models widely 